\title{
Structure and Phase Composition of the Surface Layer of Elastomers Modified by Tungsten Magnetron Sputtering
}

\author{
Lyubov F. Kalistratova a, Evgeniy A. Rogachev*a, \\ Valeriy I. Surikov a and Yuliya V. Kuznetsova ${ }^{\text {b }}$ \\ ${ }^{a}$ Omsk State Technical University \\ Omsk, Russian Federation \\ ${ }^{b}$ Surgut State University \\ Surgut, Russian Federation
}

Received 24.03.2021, received in revised form 15.06.2021, accepted 01.08.2021

\begin{abstract}
This paper contains the results of studies of the structure and composition of the surface layer of the tungsten coating of a rubber substrate. The rubber substrate is prepared on the basis two rubbers: polychloroprene rubber Denka RS-40A (Bypass 611) with a mass fraction of 0.70; the rest-BNKS-28 AMN. The deposition of tungsten on the substrate surface was carried out by magnetron sputtering on the installation «ADVAVAC VSM-200». Microscopic studies of the surface layer of the samples, decoding of X-ray images and elemental chemical analysis allowed us to determine the structure and phase composition of the surface layer depending on the time of sputtering of tungsten. It is shown that the surface layer of elastomers has a granular structure, which includes cluster formations of tungsten in the atomic state in the form of a $\beta$-modification of tungsten (W5) and individual inclusions of atomic elements that are part of the rubber substrate.
\end{abstract}

Keywords: elastomer, surface, tungsten, modification, structure, grain, cluster, X-ray, microscopic studies.

Citation: Kalistratova L.F., Rogachev E.A., Surikov V.I., Kuznetsova Yu.V. Structure and phase composition of the surface layer of elastomers modified by tungsten magnetron sputtering, J. Sib. Fed. Univ. Eng. \& Technol., 2021, 14(5), $572-582$. DOI: 10.17516/1999-494X-0334

(C) Siberian Federal University. All rights reserved

This work is licensed under a Creative Commons Attribution-Non Commercial 4.0 International License (CC BY-NC 4.0).

* Corresponding author E-mail address: evg.rogachev@yandex.ru

ORCID: 0000-0003-2622-7492 (Rogachev), 0000-0003-1146-0478 (Surikov) 


\title{
Структура и фазовый состав поверхностного \\ слоя эластомеров, модифицированных вольфрамом \\ методом магнетронного распыления
}

\author{
Л.Ф. Калистратова ${ }^{\text {a }}$ Е. А. Рогачев ${ }^{a}$, \\ В.И. Суриков ${ }^{a}$, Ю. В. Кузнецова ${ }^{0}$ \\ ${ }^{a}$ Омский государственный технический университет \\ Российская Федераиия, Омск \\ ${ }^{6}$ Сургутский государственный университет \\ Российская Федераиия, Сургут
}

\begin{abstract}
Аннотация. В данной работе представлены результаты многоплановых исследований структуры и состава поверхностного слоя вольфрамового покрытия резиновой подложки. Резиновая подложка приготовлена на основе двух каучуков: полихлоропреновый каучук Denka PS-40A (Байпрен 611) с массовой долей 0,70; остальное - БНКС-28 АМН. Нанесение вольфрама на поверхность подложки осуществляли методом магнетронного распыления на установке «ADVAVAC VSM-200». Микроскопические исследования поверхностного слоя образцов, расшифровка рентгенограмм и элементный химический анализ позволили определить структуру и фазовый состав поверхностного слоя в зависимости от времени распыления вольфрама. Показано, что поверхностный слой эластомеров имеет зернистую структуру, которая включает в себя кластерные образования вольфрама, находящегося в атомарном состоянии в виде $\beta$-модификации вольфрама (W5), и отдельные включения атомарных элементов, входящих в состав резиновой подложки.
\end{abstract}

Ключевые слова: эластомер, поверхность, вольфрам, модифицирование, структура, зерно, кластер, рентгенографические, микроскопические исследования.

Цитирование: Калистратова, Л.Ф. Структура и фазовый состав поверхностного слоя эластомеров, модифицированных вольфрамом методом магнетронного распыления / Л. Ф. Калистратова, Е. А. Рогачев, В. И. Суриков, Ю. В. Кузнецова // Журн. Сиб. федер. ун-та. Техника и технологии, 2021, 14(5). С. 572-582. DOI: 10.17516/1999-494X-0334

\section{Введение}

Эластомеры, в частности резины и резинотехнические изделия (РТИ), находят широкое практическое применение в качестве конструкционных материалов из-за их специфических свойств. Одной из актуальных задач является улучшение физико-механических, триботехнических и других эксплуатационных характеристик этих материалов.

Улучшение эксплуатационных свойств эластомеров, в частности резин, возможно их модифицированием. Любой вид модифицирования материала (объемный или модифицирование поверхности) непосредственно связан с механизмом интенсивной диссипации энергии. Подробный анализ достоинств и недостатков модифицирования эластомеров и полимерных композитов путем нанесения покрытий представлен в монографии [1]. В последнее десятилетие широкое распространение получил метод магнетронного распыления, который позволяет получать покрытия на основе уже известных материалов, но с улучшенными физико-химическими и эксплуатационными свойствами $[2,3]$. Непосредственная связь физико-химических свойств эластомеров со структурой и составом поверхностного слоя была исследована в ряде работ [4-7].

$$
-573-
$$


В них показано, что для улучшения эксплуатационных характеристик эластомеров следует развивать и совершенствовать методы нанесения защитных покрытий. Замечено, что временной процесс нанесения покрытия методом магнетронного распыления сам по себе сложный процесс, который приводит к различному состоянию структуры поверхностного слоя. В силу ряда причин вопрос остается достаточно мало изученным. Поэтому все исследования в этой области знаний актуальны.

Как правило, наиболее эффективными методами исследования структуры и элементного состава покрытий эластомеров являются электронная микроскопия, рентгенография поверхности, а также химический элементный анализ.

\section{I. Постановка задачи}

Как показали исследования, выполненные в ряде работ [2, 3], одним из эффективных методов поверхностного модифицирования резин и РТИ служит формирование на поверхности резин слоя из износостойких материалов методом магнетронного распыления. В качестве материалов мишени могут быть использованы молибден, тантал, вольфрам и другие тугоплавкие металлы. Модифицирование резины сопровождается изменением структуры и химического состава приповерхностного слоя вследствие его насыщения атомами металла мишени, что способствует улучшению эксплуатационных свойств.

В данной работе рассматриваются особенности структуры покрытий из вольфрама, нанесенных на поверхность образцов, с точки зрения рельефа, каковой является поверхность резины.

Цель данной работы - исследование структуры и состава поверхностного слоя эластомеров, модифицированных методом магнетронного распыления вольфрама в зависимости от длительности процесса. Для достижения цели были выполнены: микроскопические исследования на электронном микроскопе, рентгеноспектральный микроанализ химического состава, а также рентгеноструктурный анализ поверхностного слоя двумя методами: по стандартной методике «Theta-2Theta» и методом скользящего пучка.

\section{II. Теория}

Особенности процессов формирования покрытий из металлов при использовании ионноплазменных методов, в том числе метода магнетронного распыления, в первую очередь, связаны с механизмом интенсивной диссипации энергии. «Можно выделить три стадии формирования структуры покрытия. На первой стадии идет процесс зародышеобразования, который из-за отсутствия соответствующих термодинамических условий не переходит в массовую кристаллизацию. Вторая стадия представляет собой формирование вокруг нанокристаллических зародышей аморфных кластеров, которые - на третьей стадии - объединяются в межкристаллитную фазу с образованием диссипативной структуры. Каждая из перечисленных стадий представляет собой сложный процесс» [8]. По этой причине интересно изучить особенности структуры и состав покрытий из износостойких металлов, нанесенных на поверхность резины в зависимости от длительности распыления металла.

Толщину вольфрамового покрытия можно оценить по толщине слоя, ослабляющего интенсивность рентгеновского излучения в 10 раз в методе скользящего пучка по формуле

$$
-574-
$$




$$
t_{0}=\frac{\ln 10 \cdot \sin \alpha}{2 \mu},
$$

где $\alpha$ - угол скольжения; $\mu$ - линейный коэффициент поглощения рентгеновского излучения.

Расшифровка рентгенограмм производилась на основе закона Вульфа-Брэгга

$$
2 d \cdot \sin \Theta=n \lambda,
$$

где $\mathrm{d} / \mathrm{n}$ - межплоскостное расстояние; $\theta$ - угол дифракции; $\lambda$ - длина волны рентгеновского излучения.

\section{III. Результаты экспериментов}

В качестве объекта исследования в данной работе выбрана резина, модифицированная методом магнетронного распыления вольфрама на ее поверхность. Резина приготовлена на основе двух каучуков: полихлоропреновый каучук Denka PS-40A (Байпрен 611) с массовой долей 0,70; остальное - БНКС-28 АМН. Данную резину применяют в промышленности для изготовления покровного слоя резинокордных оболочек и различных резинотехнических изделий (РТИ). Рецептура резины подробно описана в работе [4].

Нанесение вольфрама на поверхность резины осуществляли методом магнетронного распыления на установке «ADVAVAC VSM-200» после предварительной подготовки образцов (притирки) и ионной очистки. Температура подложки поддерживалась в интервале $80-90{ }^{\circ} \mathrm{C}$. В качестве мишени использовали вольфрам высокой чистоты (от 99 \%), а в качестве технологического газа - аргон. Давление газа в камере составляло 3,3-3,4 МПа. Длительность распыления металла варьировали по времени от 1 до 55 мин с непостоянным временным шагом.

Элементный состав поверхностных покрытий резины, полученных при разной длительности распыления, представлен в табл. 1.

Микроскопические исследования поверхностного слоя образцов выполняли на растровом электронном микроскопе JEOL JCM-5700 производства компании JEOL (Япония), оснащенного энергодисперсионным спектрометром JED-2300. Микрофотографии поверхности исходной резины и резины, модифицированной вольфрамом при длительности распыления 55 мин, представлены на рис. 1 и 2 при кратности увеличения 10000 [3].

Рентгенографические исследования проводили на дифрактометре XRD-7000S в медном $K_{\alpha}$-излучении ( $\lambda=0.154$ нм) двумя методами: по стандартной методике: «Theta-2Theta» и методом скользящего пучка. Первый метод был выбран с целью исключения рефлексов малой ин-

Таблица 1. Элементный состав поверхностного слоя до и после распыления

Table 1. Elemental composition of the surface layer before and after spraying

\begin{tabular}{|c|c|c|c|c|}
\hline \multirow{2}{*}{$\begin{array}{c}\text { Длительность } \\
\text { распыления, мин }\end{array}$} & \multicolumn{4}{|c|}{ Элементный состав, масс.\% } \\
\cline { 2 - 5 } & $\mathrm{C}$ & $\mathrm{O}$ & $\mathrm{Cl}$ & $\mathrm{W}$ \\
\hline 0 & 88,32 & 1,18 & 8,80 & 36,13 \\
\hline 5 & 26,17 & 1,72 & 31,31 & 50,22 \\
\hline 55 & 27,01 & 14,57 & 7,23 & - \\
\hline
\end{tabular}


тенсивности, принадлежащих соединениям каучуков и их наполнителей (в частности, углерод и соединения цинка). В качестве иллюстрации на рис. 3 приведена дифрактограмма приповерхностного слоя исходной резины. Наблюдаемые на дифрактограмме рефлексы соответствуют соединениям $\mathrm{ZnO}$ и $\mathrm{Zn} \mathrm{S}$. Присутствие рефлексов $\mathrm{ZnO}$ и $\mathrm{ZnS}$ на дифрактограммах, естественно, затрудняет их интерпретацию. Рентгенограммы, полученные методом скользящего пучка, позволили более детально изучить особенности структуры вольфрамового покрытия и оценить глубину модифицированного вольфрамом покрытия.

Расчет межплоскостных расстояний $\mathrm{d} / \mathrm{n}$ осуществляли по дифракционным максимумам рентгенограмм, полученных по методу скользящего пучка при углах скольжения $\alpha=(5-15)$ гра-

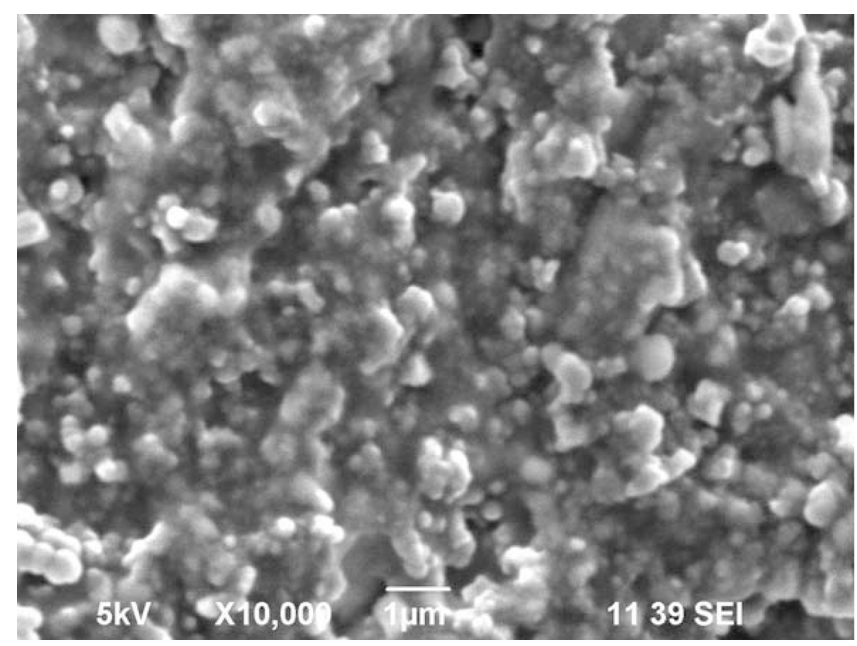

Рис. 1. Микрофотография поверхности исходной резины

Fig. 1. Surface of the initial rubber

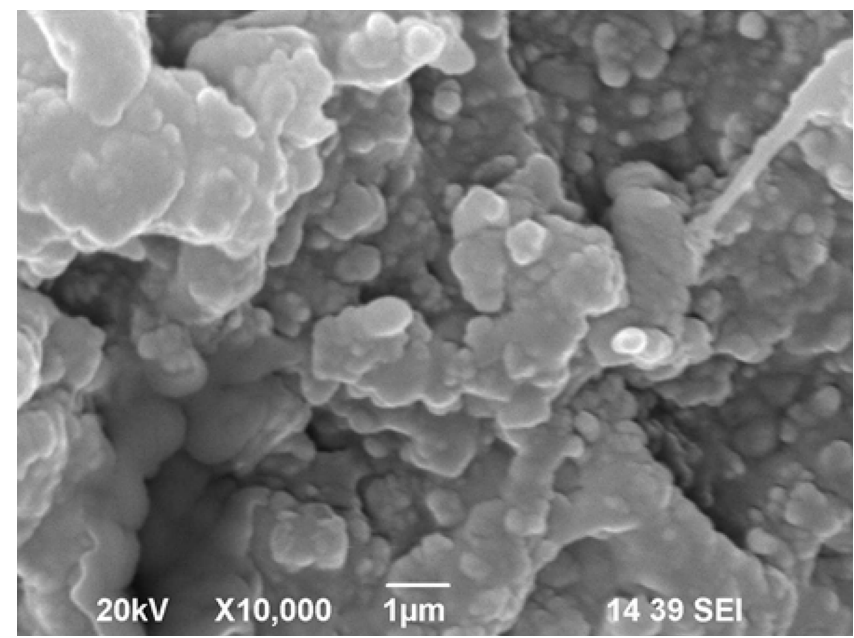

Рис. 2. Микрофотография поверхности резины, модифицированной вольфрамом (время распыления 55 мин)

Fig. 2. Surface of tungsten-modified rubber (spraying time $55 \mathrm{~min}$ ) 


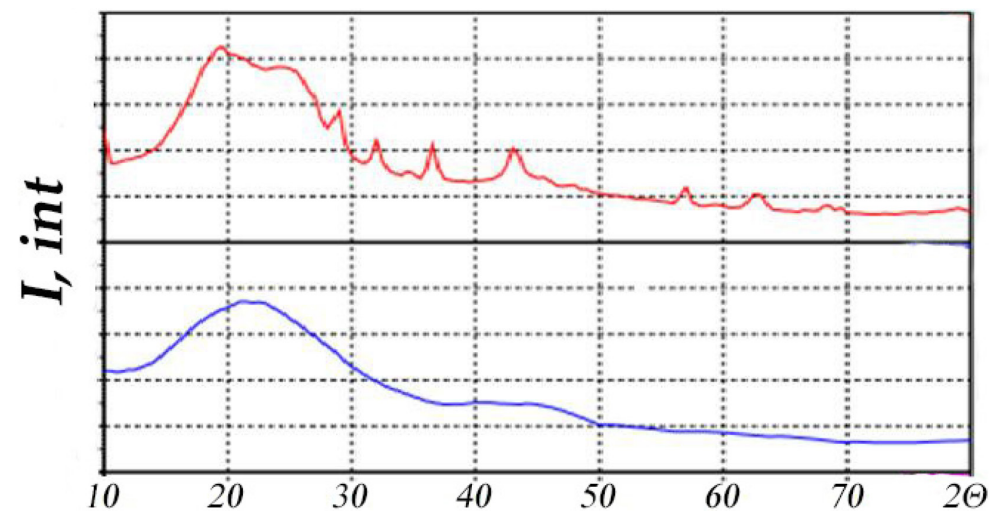

Рис. 3. Дифрактограмма поверхности исходной резины

Fig. 3. Diffraction pattern of the surface of the original rubber

дусов и находящихся в интервале дифракционных углов $(\alpha-100)^{\circ}$. Полученные значения межплоскостных расстояний $\mathrm{d} / \mathrm{n}$ усредняли и сравнивали с табличными значениями для предполагаемых фаз, присутствующих в покрытии [9].

Для наглядного представления на рис. 4 приведены усредненные профили дифрактограмм поверхностного слоя резины, модифицированной вольфрамом при длительности распыления 1, 10 и 55 мин. Сравнительный анализ этих дифрактограмм позволяет проанализировать влияние длительности распыления вольфрама на структуру и фазовый состав поверхностного слоя резины. Графическая обработка дифрактограммы для длительности распыления W 55 мин, снятая по стандартной методике «Theta-2Theta», показана на рис. 5.

Экспериментальные и расчетные значения межплоскостных расстояний для атомарного вольфрама $\mathrm{W}_{6}$ и его $\beta$-модификации $\left(\mathrm{W}_{5}\right)$ приведены в табл. 2.

\section{IV. Обсуждение результатов}

По результатам химического анализа поверхностного слоя вольфрамового покрытия можно сделать вывод о том, что поверхностный слой покрытия содержит атомарный углерод, хлор и кислород, по-видимому, образующиеся как продукты распада макромолекул резиновой подложки. Их массовое соотношение по-разному изменяется в зависимости от длительности распыления: концентрация кислорода и хлора увеличивается, углерода - уменьшается (табл. 1). При малой длительности распыления (до 5 мин) в поверхностном слое покрытия содержится также атомарный вольфрам, который затем с увеличением длительности распыления накапливается: при длительности распыления 55 мин его содержание увеличилось в 1.4 раза. Следует отметить, что атомарный вольфрам может находиться в двух модификациях: $\mathrm{W}_{6}$ и $\mathrm{W}_{5}$, причем $\mathrm{W}_{5}$ обозначается как $\beta$-фаза вольфрама [9].

Сравнение микрофотографий, представленных на рис. 1 и 2, показывает, что поверхностный слой покрытия обогащен наличием кластеров разной формы и размеров, которые зависят от длительности распыления: линейный размер кластеров растет с увеличением длительности распыления. Детальный анализ демонстрирует, что сами кластеры состоят из более мелких образований - зерен. В целом можно сказать, что покрытие из вольфрама имеет зернистую 


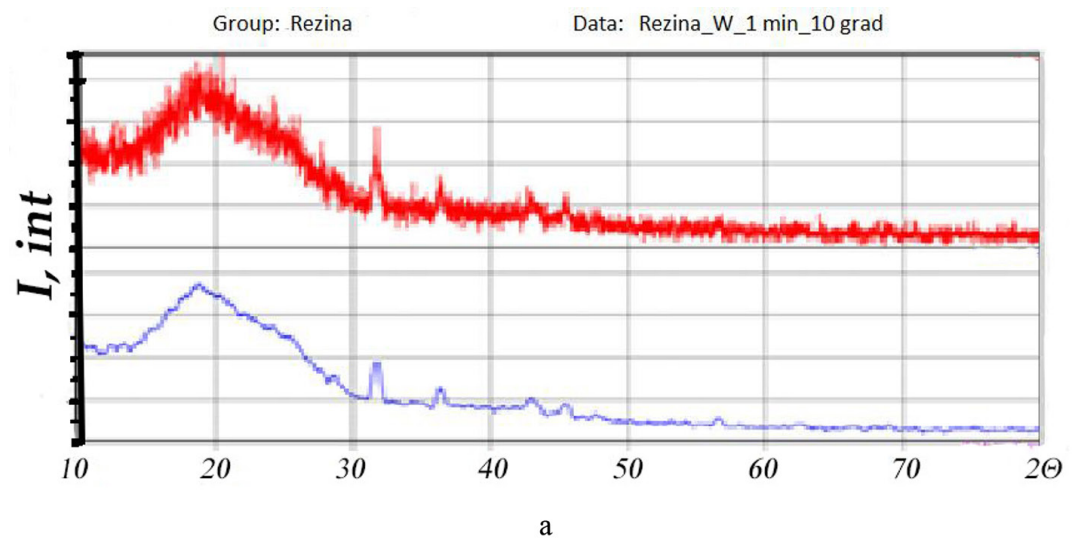

a

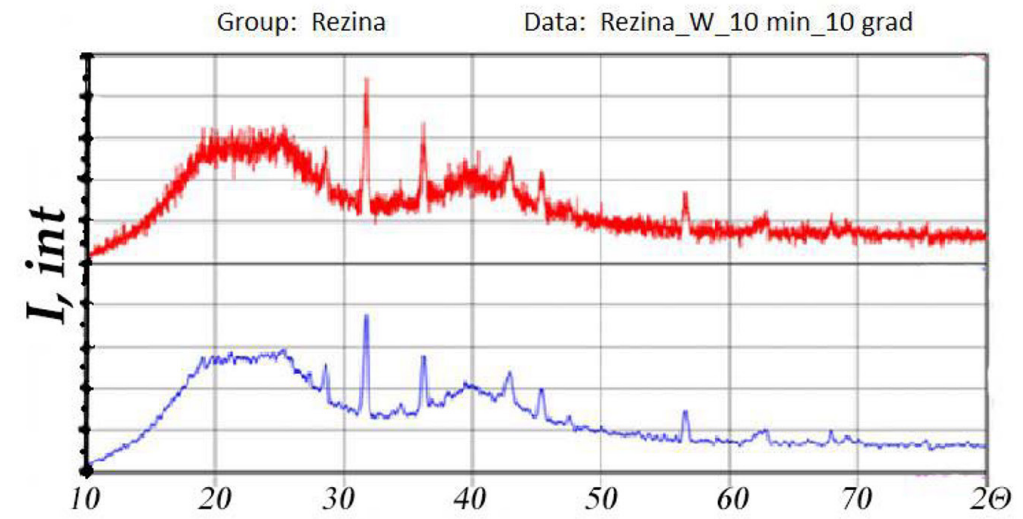

b)

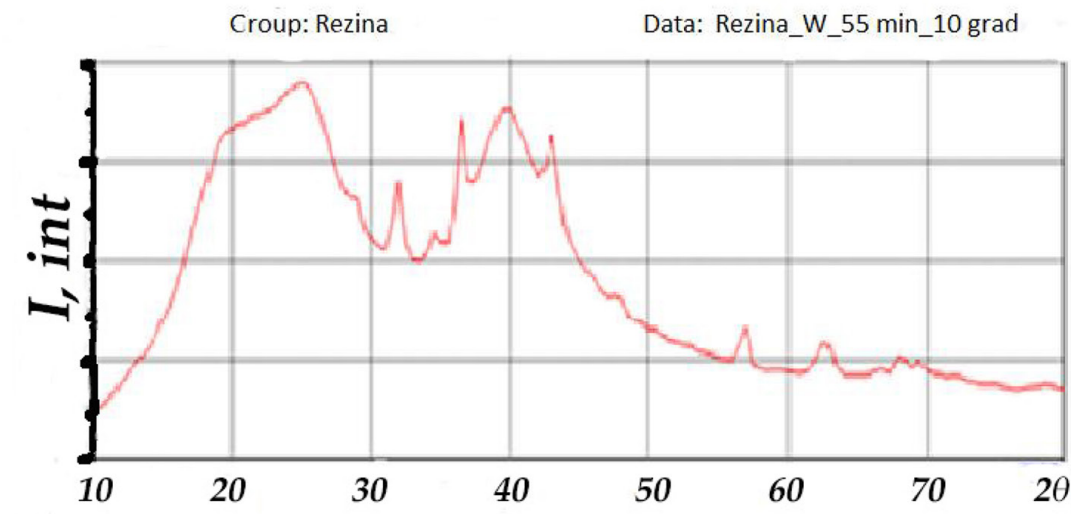

c)

Рис. 4. Дифрактограммы поверхностного слоя резины, модифицированной W при длительности распыления: $\mathrm{a}-1$ мин; $\mathrm{b}-10$ мин; $\mathrm{c}-55$ мин (угол скольжения $\alpha=10^{\circ}$ )

Fig. 4. Diffraction patterns of the surface layer of rubber modified with $\mathrm{W}$ at the duration of spraying: $\mathrm{a}-1 \mathrm{~min}$; $\mathrm{b}-10 \mathrm{~min} ; \mathrm{c}-55 \mathrm{~min}$ (sliding angle $\alpha=10^{\circ}$ ) 


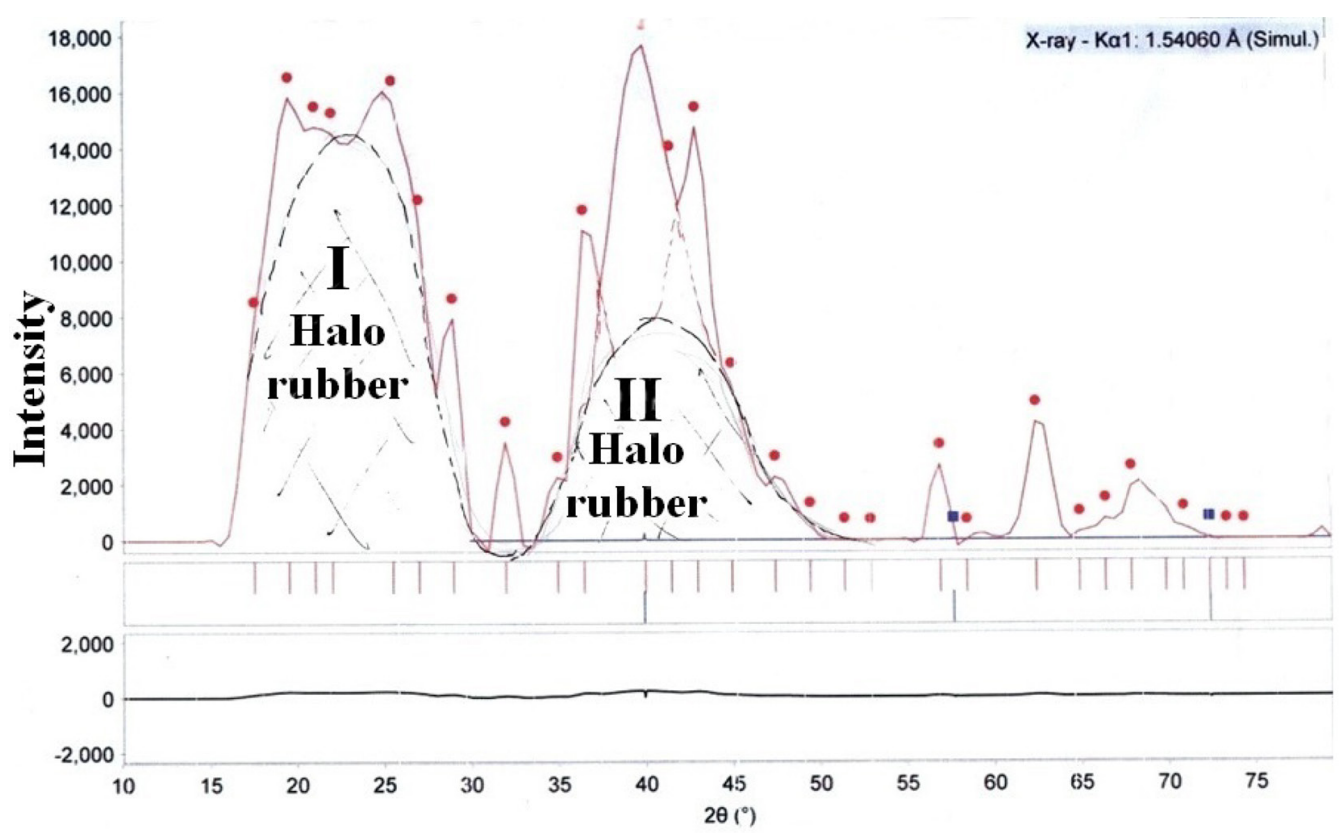

Рис. 5. Графическая обработка дифрактограммы поверхностного слоя резины, модифицированной $\mathrm{W}$ при длительности распыления 55 мин (методика сьемки «Theta-2Theta»)

Fig. 5. Graphical processing of the diffraction pattern of the surface layer of rubber modified with $\mathrm{W}$ at a spraying duration of 55 min (shooting method «Theta -2 Theta»)

Таблица 2. Фазовый состав вольфрамового покрытия

Table 2. Phase composition of the tungsten coating

\begin{tabular}{|c|c|c|c|}
\hline $2 \theta$, град. & $(\mathrm{d} / \mathrm{n})_{\text {эксп. }}, \mathrm{Hм}$ & $(\mathrm{d} / \mathrm{n})_{\text {табл. }} \mathrm{W}_{6}, \mathrm{Hм}$ & $\begin{array}{c}(\mathrm{d} / \mathrm{n})_{\text {табл. }} \beta-\mathrm{W}\left(\mathrm{W}_{5}\right) \\
\text { нм }\end{array}$ \\
\hline 19.12 & 0.464 & & \\
\hline 19.20 & 0.462 & & \\
\hline 19.25 & 0.461 & & \\
\hline 25.79 & 0.345 & & \\
\hline 28.97 & 0.300 & & 0.252 \\
\hline 32.00 & 0.279 & & 0.225 \\
\hline 36.55 & 0.246 & & 0.206 \\
\hline 39.70 & 0.227 & & \\
\hline 42.50 & 0.212 & & \\
\hline 43.15 & 0.209 & & \\
\hline 48.00 & 0.189 & & \\
\hline 57.00 & 0.161 & & 0.158 \\
\hline 63.00 & 0.147 & & 0.129 \\
\hline 66.00 & 0.141 & & 0.135 \\
\hline 69.00 & 0.136 & & \\
\hline 79.00 & 0.121 & & \\
\hline & & & \\
\hline
\end{tabular}


структуру. Оценочный расчет по формуле (1) для вольфрама W показывает, что толщина вольфрамового покрытия резины при угле скольжения $\alpha=10^{\circ}$ равна 580 нм при расчетном коэффициенте поглощения $1740 \mathrm{~cm}^{-1}$.

Более детальные сведения о структурно-фазовом состоянии вольфрамового покрытия дают методики рентгеноструктурного анализа. По внешнему виду дифрактограмм покрытий, полученных при разной длительности напыления, можно судить о том, что основной элемент поверхности - резина - находится в аморфном состоянии (рис. 3,4$)$. Это заметно по наличию на рентгенограммах участков аморфных гало, находящихся в дифракционных углах $2 \theta=(20-25)^{\circ}$ и $2 \theta=(40-45)^{\circ}$. Изопреновый каучук (в частности, резина) может относиться к аморфным и аморфно-кристаллическим полимерным материалам с очень низкой степенью кристалличности, равной 0.1-0.4. Возможные конфигурации углеводородной цепи натурального каучука отличаются по периоду идентичности (расстояние между двойными связями углеводородной цепи, что позволяет делать выводы о регулярности строения макромолекулы и наличии изомеров). Из литературных источников известно, что период идентичности у натурального каучука имеет значение $\mathrm{d} / \mathrm{n}=0.816$ нм. Это значение получено методом малоуглового рассеяния (МУР). Аморфное кольцо (аморфное гало первого порядка) соответствует отражению в первом порядке от плоскостей с малыми миллеровскими индексами, например от плоскостей (001), и расположено в области дифракционных углов до $5^{\circ}\left(2 \theta=10.8^{\circ}, \sin \theta_{001}=0.0944\right)$, поэтому на обычных рентгенограммах, полученных в больших углах дифракции, оно не наблюдается. Исходя из теории рентгеноструктурного анализа $\left(\sin ^{2} \theta_{002}=4 \sin ^{2} \theta_{001}, \sin ^{2} \theta_{003}=9\right.$ $\left.\sin ^{2} \theta_{001}\right)$ аморфное гало второго, третьего и четвертого порядков должны находиться в угловых интервалах дифракционных углов $2 \theta=21.8,32.9$ и $44.3^{\circ}$. Таким образом, на представленных дифрактограммах наблюдаются аморфные гало второго и четвертого порядков от основного элемента покрытия - резины, так как максимумы аморфных гало, обозначенных на рис. 5 как гало I и II, приходятся на углы дифракции $2 \theta=22$ и $42^{\circ}$. По наличию аморфных гало можно также отметить, что резина не просто находится в аморфном состоянии, а имеет некоторую степень упорядочения по отражающим плоскостям (001).

Расшифровка дифрактограммы, представленной на рис. 5, позволила внести некоторые дополнения в фазовый состав покрытия. В чистом виде атомарный вольфрам имеет валентность 6 , но в соединениях валентность может быть разной: от 0 до 5. В покрытии вольфрам наблюдается в двух видах $-\mathrm{W}_{5}$ и $\mathrm{W}_{6}$. Обе модификации вольфрама имеют кубическую решетку: $\mathrm{W}_{6}$ имеет решетку простого куба с параметром ячейки а $=0.316$ нм, a $\mathrm{W}_{5}$ ( $\beta$-модификация) - объемноцентрированную кубическую решетку с параметром ячейки а $=0.5048$ нм. На рентгенограмме сильнее проявляется наличие кристаллической фазы $\mathrm{W}_{5}$ по сравнению с $\mathrm{W}_{6}$ (табл. 2).

\section{Выводы и заключение}

1. Элементным химическим анализом поверхности вольфрамового покрытия на резиновой подложке установлено наличие следующих элементов: атомарных углерода, кислорода, хлора и ванадия.

2. Рентгенографическим методом исследован фазовый состав реальной поверхности вольфрамового покрытия: получена однородная аморфно-кристаллическая зернистая структура поверхности, включающая в себя кластерные кристаллические образования ванадия: $\mathrm{W}_{5}$ и $\mathrm{W}_{6}$. 
3. Применением метода скользящего пучка рентгеновских лучей произведена оценка толщины модифицированного вольфрамом слоя на основании расчетных значений линейных коэффициентов поглощения отдельных элементов: толщина слоя сравнима с глубиной проникновения рентгеновских лучей.

4. Длительность напыления вольфрамом приводит к увеличению массовой доли указанных кристаллических фаз вольфрама.

5. По наличию аморфных гало можно также отметить, что резина не просто находится в аморфном состоянии, а имеет некоторую степень упорядочения по отражающим плоскостям (001).

Итак, обогащение поверхности резины вольфрамом методом магнетронного распыления приводит к формированию такого структурно-фазового состава покрытия, которое обеспечивает упрочнение резины за счет появления в ней нескольких кристаллических образований кластерной формы самого вольфрама.

\section{Благодарность / Acknowledgement}

Авторы выражают благодарность инженеру Е. П. Целых за предоставленные для исследования образцы.

The authors are grateful to the engineer E. P. Celih for the provided sample studies.

\section{Список литературы / References}

[1] Friedrich K., Schlarb A.K. Tribology of Polymeric Nanocomposites: Friction and Wear of Bulk Materials and Coatings / 2nd Edition, Butterworth-Heinemann, Elsevier, 2013. 832 p. ISBN-13: 978-0-444-59455-6- (Tribology and Interface Engineering).

[2] Берлин Б. В., Сейдман Л. А. Получение тонких пленок реактивным магнетронным распылением. М.: Техносфера, 2014. 256 c. [Berlin B. V., Seydman L. A. Obtaining thin films by reactive magnetron sputtering, Moskva, Tehnosphera, 2014, 256 p. (in Russian)]

[3] Витязь П.А., Солнцева К. А. Технологии конструкционных наноструктурных материалов и покрытий, Минск: Беларус. навука, 2011. 283 с. [Vityaz P. A., Solnzeva K. A. Technologies for structural nanostructured materials and coatings, Minsk, Belarus.navuka, 2011, 283 p. (in Russia)]

[4] Целых Е.П. Влияние режимов ионно-плазменного распыления на структуру и свойства износостойких покрытий на резиновой подложке, дис. ... канд. техн. наук. Омск, 2015. 170 c. [Zelyh E. P. Influence of ion-plasma sputtering modes on the structure and properties of wearresistant coatings on a rubber substrate, Thesis ... cand. of tech. Sci. Omsk, 2015, 170 p. (in Russia)]

[5] Briscoe B. J., Shina S.K. Tribology of polymeric solids and their composites, Chapter 10, in Wear-Materials, Mechanisms and Practice (ed. G. W. Stachowiak), Wiley, NewYork, 2005, pp. 223-267.

[6] Friedrich K., Zhang Z., Schlarb A. K., Effects of various fillers on the sliding wear of polymer composites. Compos. Sci. Technol., 2005, 65, 2329-2343.

[7] Brostow W., Keselman M., Mironi-Harpaz I., Narkis M., Peirce R., Effects of carbon black on tribology of blends of poly(vinylidene fluoride) with irradiated and non-irradiated ultrahigh molecular weight polyethylene. Polymer, 2005, 46, 5058-5064.

[8] Еремин Е.Н., Юров В.М., Гученко С.А., Лауринас В.Ч. Прогнозирование свойств нанокристаллических покрытий, Динамика систем, механизмов и машин, 2016, 1(3),

$$
-581-
$$


190-195 [Eremin E. N., Urov V.M., Guchenko S.A., Laurinas V. Ch. Prediction of the properties of nanocrystalline coatings, Dynamics of systems, mechanisms and machines, 2016. 1(3), 190-195 (in Russia)]

[9] Миркин Л.И. Справочник по рентгеноструктурному анализу поликристаллов. М.: Госуд. изд-во физ.-мат. лит-ры, 1961. 864 с. [Mirkin L.I. Handbook on X-ray structural analysis of polycrystals, Moskva, Gosud. izd-vo phis.-math. lit-ri, 1961, 684 p. (in Russia)] 